\title{
Schizophrenia and smoking: impact on negative symptoms*
}

\author{
Miriam Saliba', Shafika Assaad', Chadia Haddad², Souheil Hallit 2,3,4,5, Dory Hachem², Georges Haddad²,5 \\ ' Lebanese University, Faculty of Sciences, Beirut, Lebanon \\ ${ }^{2}$ Psychiatric Hospital of the Cross, Jal Eddib, Lebanon \\ ${ }^{3}$ Lebanese University, Faculty of Pharmacy, Beirut, Lebanon \\ ${ }^{4}$ Saint Joseph University, Faculty of Pharmacy, Beirut, Lebanon \\ ${ }^{5}$ Holy Spirit University, Faculty of Medicine and Medical Sciences, Kaslik, Lebanon
}

\section{RESUMEN}

Antecedentes: se ha planteado la hipótesis de que los pacientes con esquizofrenia emplean la nicotina para reducir los síntomas negativos de su enfermedad y para mejorar su función cognitiva; sin embargo, no existe evidencia concluyente en la literatura sobre el vínculo entre el consumo de nicotina y la disminución de los síntomas negativos de la enfermedad. Objetivo: investigar los efectos de la nicotina en la expresión de síntomas negativos en pacientes con esquizofrenia, tanto fumadores como no fumadores. Método: se realizó un estudio transversal con 100 pacientes diagnosticados con esquizofrenia (54 fumadores y 46 no fumadores) en el Hospital Psiquiátrico de la Cruz, en Líbano, entre abril y agosto de 2016. Se utilizaron los instrumentos CDSS, PANSS y FTND para evaluar parámetros clínicos. Se emplearon las pruebas $t$ de Student, ANOVA y chi-cuadrada para las comparaciones. Resultados: la edad media de los fumadores fue de 47.16 años $(S D=7.14)$ y la de los no fumadores de 47.02 años ( $S D=7.9$ ). $69.8 \%$ de los fumadores y $45.7 \%$ de los no fumadores fueron hombres. La alta dependencia de la nicotina se relacionó con la disminución de síntomas negativos evaluados con el PANSS entre los dos grupos $(p<.001)$; no se encontraron diferencias significativas ni en los síntomas positivos ni con los cognitivos ( $p>.05$ para ambas variables). Discusión y conclusiones: este estudio es el primero en investigar la relación entre la expresión de los síntomas negativos y el tabaquismo en pacientes con esquizofrenia en Líbano. El tabaquismo es un proceso complejo que involucra aspectos psicopatológicos, bioquímicos y neurofarmacológicos; las tasas de tabaquismo son considerablemente altas entre pacientes con esquizofrenia, por lo que son necesarios más estudios para reconocer estos hallazgos y sus bases.

Palabras clave: tabaquismo, dependencia de la nicotina, esquizofrenia, síntomas negativos.

\section{ABSTRACT}

Introduction: it has been hypothesized that individuals with schizophrenia use nicotine to reduce negative symptoms and improve cognitive function. There is an inconsistency in the literature suggesting that nicotine could help decrease negative symptoms in schizophrenic patients. Objective: to investigate the effects of nicotine on the expression of the negative symptoms in smokers and non-smokers with schizophrenia. Methods: a cross sectional study, conducted between April and August 2016, 100 inpatients with schizophrenia (54 smokers and 46 non-smokers) diagnosed according to DSM-V, at Psychiatric Hospital of the Cross Lebanon, were compared to changes in clinical parameters using CDSS, PANSS, and nicotine dependence using FTND. The Student's t-test was used to compare between 2 groups, while the ANOVA test was used to compare between 3 or more groups. For categorical variables, the chi-2 test was used. Results: the mean age was 47.16 years $(S D=7.14)$ for smokers compared to 47.02 years $(S D=7.92)$ for non-smokers. $64.8 \%$ of smokers were males versus $45.7 \%$ of non-smokers. Smoking (high nicotine dependence) significantly decreases the PANSS negative symptoms score between the 2 groups ( $p<.001$ ), whereas it did not show a significant difference for the positive and the cognitive symptoms total score ( $p>.05$ for both variables). Discussion and conclusion: this study is the first to investigate the relationship between the expression of negative symptoms in individuals with schizophrenia and smoking in Lebanon. Cigarette smoking rates remain remarkably high in patients with schizophrenia. Smoking is a complex process which involves psychopathological, biochemical and neuropharmacological aspects among schizophrenic patients. Further studies are needed to acknowledge these findings and the reasons behind it.

Keywords: smoking, nicotine dependence, schizophrenia, negative symptoms.

\section{Corresponding author:}

Souheil Hallit. Research Department. Psychiatric Hospital of the Cross, P.O. Box 60096, Jall-Eddib, Lebanon.

E-mail: souheilhallit@hotmail.com

Received: November 14, 2016

Accepted: April 12, 2017

DOI: $10.28931 /$ riiad.2017.1.04

* This work has been done in the frame of the "Behavioral and Cognitive Neuroscience Master 2 program", Faculty of Sciences, Lebanese University. 


\section{INTRODUCTION}

High nicotine dependence is highly prevalent in persons with schizophrenia and schizoaffective disorder, as compared to the general population (De Leon \& Diaz, 2005; Dickerson et al., 2013; Kelly \& McCreadie, 2000; Morisano, Bacher, Audrain-McGovern, \& George, 2009; Šagud et al., 2009). These elevated rates are also higher than the rates observed among patients with other psychiatric illness (Beck, Baker, \& Todd, 2015; De Leon \& Diaz, 2005). A meta-analysis suggested that the odds for schizophrenic patients to be current smokers are five times higher than those for the general population (De Leon \& Diaz, 2005). This high prevalence has been noted in a variety of countries, which suggests that a biological factor may be responsible for making these patients more susceptible to smoking (De Leon \& Diaz, 2005). One of these factors is nicotine, the main psychoactive component of tobacco and responsible for its addictive properties, that modifies the brain function via its interaction with the nicotinic acetylcholine receptors (Changeux, 2010; Dome, Lazary, Kalapos, \& Rihmer, 2010).

A strong association exists between schizophrenia and tobacco use (Kao, Liu, Cheng, \& Chou, 2011). Many schizophrenic patients use nicotine as a self-medication given the immediate pharmaco-therapeutic effects of nicotine, which include its sedative, stimulant, and sensorimotor manipulation properties (Al-Halabí et al., 2017; Segarra et al., 2011). It improves the visuospatial working memory and reduces the attentional deficits of these subjects (Dépatie et al., 2002; Harris et al., 2004; Jacobsen et al., 2004; Sacco et al., 2005), as well as the deficits in sensory processing (Leonard \& Adams, 2006). In addition, patients who smoke have lower prevalence and severity of extrapyramidal symptoms compared to patients who do not, by reducing the adverse effects of antipsychotic medication (Carrillo et al., 2003; De Leon \& Diaz, 2005; Dervaux \& Laqueille, 2008). An explanation for the association between schizophrenia and nicotine, is that people suffering from schizophrenia smoke to reduce their positive (Goff, Henderson, \& Amico, 1992; Ziedonis, Kosten, Glazer, \& Frances, 1994) or negative symptoms (Hall et al., 1995) and to enhance their cognitive functioning (Lyon, 1999). There is an inconsistency in the literature and scarce clinical data suggesting that nicotine could help decrease negative symptoms in schizophrenic patients (Aguilar, Gurpegui, Diaz, \& De Leon, 2005). A case-control study, done by Zhang et al. (2012) found that schizophrenic patients who smoke had lower negative symptoms compared with non-smokers (Zhang et al., 2012). A study done by Dixon et al. (2007) showed that schizophrenic patients with greater smoking severity had an increased positive symptoms, decreased negative symptoms and fewer extra pyramidal side effects. A study done by Krishnadas, Jauhar, Telfer, Shivashankar and McCreadie (2012) showed that those with severe nicotine dependence assessed by FTND score had greater scores on the positive subscale of PANSS, and those with mild-moderate dependence had greater scores on the PANSS negative subscale. A study done by Barnes et al. (2006) showed that there are no significant differences between smoking and non-smoking groups with regard to Positive and Negative Symptom Scale.

Furthermore, cholinergic deficits in basal forebrain structures and their projections in schizophrenia may be of particular importance to the cognitive dysfunction given their known functional roles in conscious awareness, and components of information processing, including attention, working memory, encoding, memory consolidation, and retrieval (Gold, 2003; Perry, Walker, Grace, \& Perry, 1999).

However, there is a scarceness of research directly assessing smoking and symptoms in schizophrenia. The degree of how smoking affects positive, negative and cognitive symptoms in schizophrenia remains unclear. This study investigates the effects of nicotine on the expression of the negative symptoms in smokers and non-smokers with schizophrenia.

\section{METHODS}

\section{Study design and participants}

A cross sectional study was conducted between April and August 2016, at the Psychiatric Hospital of the Cross, Lebanon. The study protocol was reviewed and approved by the research and ethics committee of the hospital. Participants or their legal guardians approved and signed a written informed consent form.

The study included 100 participants aged 20-60 years, 54 smokers (who smoke at least 20 cigarettes or more per day) and 46 nonsmokers who were stable, hospitalized during the period of the study (1-33 years). These participants were diagnosed with Schizophrenia according to the Diagnostic and Statistical Manual of Mental Disorder, Five Edition (American Psychiatric Association, 2013). Patients included in the study were taking typical (haloperiodol, chlorpromazine) and atypical antipsychotics (olanzapine, risperidone, quetiapine), at chlorpromazine equivalent doses. Patients diagnosed with mental retardation, schizophrenic or schizoaffective disorders, with concurrent depressive episodes, taking clozapine, treated with typical medication or those who consume alcohol or other drugs were excluded from the study.

Patients with schizoaffective disorders have more positive symptoms, patients with depressive episodes 
have more negative symptoms than patients with other types of schizophrenia and we cannot know if the symptoms got better because of nicotine or not, thus, were excluded from this study. We also excluded typical antipsychotics since they only work on the positive symptoms and not on the negative ones.

\section{Questionnaire and variables}

Demographic information (age, gender, marital status, educational level, socio-economic level) and clinical information of the participants were collected from medical records.

Three types of questionnaires were carried out by specialized mental health professionals: The first scale, the Calgary Depression Scale for Schizophrenia (Addington, Addington, \& Maticka-Tyndale, 1993) was used to determine if the patient presented a depressive episode for the past two weeks; in that case, patients were excluded from the study. This scale consists of nine questions concerning depression, self-depreciation, hopelessness, guilty ideas and reference, pathological guilt, morning depression, early wakening, suicide and observed depression. The answers score varied between 0 and 3 , with 0 meaning the absence of symptoms and 3 meaning severe symptoms. The total score of these nine questions would indicate the presence or the absence of a depressive episode. The patient was considered to present a depressive episode with a total score more than 5 over the nine questions of the Calgary Depression Scale for Schizophrenia (Addington et al., 1993).

The second scale, the PANSS score (Kay, Flszbein, \& Opfer, 1987), was used to assess and identify psychotic symptoms severity. It is particularly useful to track changes in positive and negative symptoms. The PANSS includes 30 items, divided into 3 scales:

a) The positive scale contains 7 questions used to assess the degree of presence of positive symptoms including delusions, conceptual disorganization, hallucinatory behavior, excitement, grandiosity, hostility, suspiciousness, and persecution.

b) The negative scale contains 7 questions used to assess the degree of negative symptoms including blunted affect, emotional withdrawal, poor rapport, passive apathetic social withdrawal, difficulty in abstract thinking, lack of spontaneity and flow of conversation and stereotyped thinking.

c) The psychopathological scale contains 16 questions used to assess physical complaints, anxiety, guilty, tension, depression, posturing, disorientation, unusual thought content, insight, impulse control and social avoidance.
Each question was scored from 1 to 7 as follows: $1=$ absent, 2 = minimal, 3 = mild, $4=$ moderate, $5=$ moderately severe, $6=$ severe and $7=$ extreme. The sum of the results for each question was assessed to give the total score for each part (Kay et al., 1987).

Patients were compared to changes in clinical parameters using the PANSS scale.

The Fagerström Test for Nicotine Dependence (FTND) (Heatherton, Kozlowski, Frecker, \& Fagerström, 1991) was used to assess nicotine dependence among smokers with schizophrenia. This scale is composed of 6 questions concerning the number of cigarettes, smoking urge, frequent time of smoking, difficulty to refrain or not smoking. The total score for each patient enabled us to classify patients into low dependence (score 1-2), low to moderate dependence (score 3-4), moderate dependence (score 5-7) and high dependence (score of 8 or more) (Heatherton et al., 1991).

\section{Statistical analysis}

Descriptive statistics were calculated for all study variables. This includes the mean and standard deviation for continuous measures, counts, and percentages for categorical variables. Pearson correlation coefficients were used to correlate between quantitative variables. The statistical package SPSS version 23 was used for all statistical analysis. Statistical significance was set at $p<.05$

\section{RESULTS}

Out of 130 patients, we approached, 100 (76.92\%) accepted to enter the study. Table 1 summarizes the socio-demographic characteristics between smokers and non-smokers schizophrenic patients. The mean age was 47.16 years $(S D=7.14)$ for smokers compared to 47.02 years $(S D=7.92)$ for non-smokers. The sample included $64.8 \%$ of male smokers versus $45.7 \%$ of non-smokers. The mean duration of hospitalization was 7.72 years $(S D=4.09)$ for smokers, compared to $12.54(S D=9.42)$ years for non-smokers. The majority (75.9\%) of smoking patients were single, with a mean number of cigarettes per day of 32.25 ( $S D=11.84)$, whereas almost all non-smokers were single, with 6.19 mean number of cigarettes daily $(S D=6.20)$. More than $40 \%$ of smokers had a primary level of education, versus $45.7 \%$ of non-smokers having a complementary one. It is worth noting that more than half of both groups had a low socioeconomic level. A significant difference between the 2 groups was found for mean duration of hospitalization, the number of cigarettes per day and the marital status. 
Table 1

Sociodemographic and socioeconomic characteristics between smoking and non-smoking schizophrenic patient

\begin{tabular}{|c|c|c|c|}
\hline Factor & $\begin{array}{c}\text { Smokers }(n=54) \\
n(\%) \text { or } M(S D)\end{array}$ & $\begin{array}{c}\text { Non-smokers }(n=46) \\
n(\%) \text { or } M(S D)\end{array}$ & $p$ value \\
\hline Age in years & $47.16(7.14)$ & $47.02(7.92)$ & .924 \\
\hline \multicolumn{4}{|l|}{ Gender } \\
\hline Male & $35(64.8 \%)$ & $21(45.7 \%)$ & \multirow{2}{*}{.054} \\
\hline Female & $19(35.2 \%)$ & $25(54.3 \%)$ & \\
\hline Hospitalization in years & $7.72(4.09)$ & $12.54(9.42)$ & .001 \\
\hline Number of cigarettes per day & $32.25(11.84)$ & $6.19(6.20)$ & $<.001$ \\
\hline \multicolumn{4}{|l|}{ Marital status } \\
\hline Single & $41(75.9 \%)$ & $44(95.7 \%)$ & \multirow{3}{*}{.011} \\
\hline Married & $11(20.4 \%)$ & $2(4.3 \%)$ & \\
\hline Divorced & $2(3.7 \%)$ & $0(0 \%)$ & \\
\hline \multicolumn{4}{|l|}{ Educational level } \\
\hline Primary & $22(40.7 \%)$ & $16(34.8 \%)$ & \multirow{4}{*}{.859} \\
\hline Complementary & $20(37 \%)$ & $21(45.7 \%)$ & \\
\hline Secondary & $9(16.7 \%)$ & $7(15.2 \%)$ & \\
\hline University & $3(5.6 \%)$ & $2(4.3 \%)$ & \\
\hline \multicolumn{4}{|l|}{ Socio-economic level } \\
\hline Low & $30(55.6 \%)$ & $30(65.2 \%)$ & \multirow{3}{*}{.657} \\
\hline Medium & $21(38.9 \%)$ & $14(30.4 \%)$ & \\
\hline High & $3(5.6 \%)$ & $2(4.3 \%)$ & \\
\hline
\end{tabular}

Table 2

PANSS ${ }^{a}$ scores between smoking and non-smoking schizophrenics

\begin{tabular}{cccc}
\hline & Smoker & Non-smoker & $p$ value \\
\hline Factor & $M(S D)$ & $M(S D)$ & .151 \\
PANSS positive symptoms & $16.07(4.95)$ & $14.73(4.27)$ & $<.001$ \\
PANSS negative symptoms & $13.42(4.05)$ & $17.54(6.09)$ & .196 \\
\hline
\end{tabular}

a PANSS = Positive and Negative Syndrome Scale

\section{Description of Calgary scale}

The distribution of the results of Calgary scale among patients was as follows: fifteen (15\%) patients had Calgary score of $1 ; 38(38 \%)$ patients had a Calgary score of 2, while $31(31 \%)$ patients had a Calgary score of 3 ; $12(12 \%)$ patients had a score of 4 and 4 patients (4\%) had a score of 5 .

\section{Smoking and PANSS symptoms}

Table 2 displays the PANSS scores and smoking in our schizophrenic patients' sample. The results showed that a significantly lower mean PANSS negative symptoms score was found in the smoking group (13.42), compared to the non-smoking group $(17.54 ; p<.001)$, whereas no significant difference was found for the positive and the cognitive symptoms total score $(p>.05$ for both variables).

\section{Description of FTND scale}

Table 3 shows the categories of patients according to the FTND score and correlation with PANSS symptoms. Eleven percent of our smoking patients had a low to moderate dependence, while $44.4 \%$ had a moderate and high de- 
Table 3

Categories of patients according to the FTND ${ }^{a}$ score and correlation with PANSS ${ }^{b}$ symptoms

\begin{tabular}{lc}
\hline FTND category & $n(\%)$ \\
\hline Low to moderate dependence & $6(11.1 \%)$ \\
Moderate dependence & $24(44.4 \%)$ \\
High dependence & $24(44.4 \%)$ \\
\hline
\end{tabular}

\begin{tabular}{lcc}
\hline Correlation of FTND score with PANSS symptoms & Correlation factor & $p$ value \\
\hline Negative symptoms & -.293 & .031 \\
Positive symptoms & -.234 & .088 \\
Cognitive symptoms & -.124 & .373 \\
\hline
\end{tabular}

a FTND: Fagerström Test for Nicotine Dependence

b PANSS: Positive and Negative syndrome scale

pendence respectively. Furthermore, the FTND score was significantly correlated with the PANSS negative symptoms score $(r=-.293 ; p=.031)$, while it tended to significance with the PANSS positive symptoms score $(r=-.234$; $p=.088)$. In addition, no significant correlation was found between the FTND score and the PANSS general psychopathological symptoms score $(r=-.124 ; p=.373)$.

\section{DISCUSSION AND CONCLUSION}

This study examined the effect of cigarette smoking among individuals with schizophrenia. The principal findings suggest that a significantly lower mean of PANSS negative symptoms score was found in the smoking group, compared to the non-smoking group. These relationships emerged despite no significant differences between smokers and nonsmokers on demographic variables, educational and socio-economic levels. Moreover, the reduced expression of negative symptoms was related to increased levels of nicotine dependence, as assessed by the FTND scale. Therefore, our results revealed a dose dependence; as cigarette smoking increases, the nicotine dependence will increase whereas the negative symptoms among schizophrenic patients who smoke will decrease.

Cigarette smoking causes considerable morbidity and mortality in patients with schizophrenia (Kelly \& McCreadie, 2000). The most common causes of morbidity and mortality in people with schizophrenia are cardiovascular and respiratory disease, both smoking-related (De Leon \& Diaz, 2005; Mortensen \& Juel, 1993).

It has been also hypothesized that individuals with schizophrenia use nicotine to reduce negative symptoms and improve cognitive function via reducing the degradation of dopamine and enhancing the effects of nico- tine-mediated dopamine release, particularly in frontalsubcortical circuitry (mesocortical dopamine pathways; Drew, Derbez, \& Werling, 2000; Glassman, 1993; Nomikos et al., 2000; Sandyk \& Kay, 1990). Negative symptoms have been considered to be related to hypo-dopaminergic state, while it has been found that nicotine reduces negative symptoms by increasing dopamine in the brain (Glassman, 1993).

The effects of smoking on reducing negative symptoms may be due to a pharmacological effect of the small amount of nicotine produced by the cigarette (Smith, Singh, Infante, Khandat, \& Kloos, 2002). The mechanisms include possible regulation of central dopamine availability by pharmacodynamic and pharmacokinetic processes (Krishnadas et al., 2012). The nicotine-induced release of dopamine in the mesocortical system results in improved cognitive performance and a decrease in negative symptoms (George, 2007). In addition, the medication administrated to schizophrenic patients blocks the dopamine receptors. Therefore, smoking increases dopamine concentration by inducing its release and inhibiting its degradation (Scott et al., 2007).

Other authors have suggested that worsening of positive symptoms may be associated with the dopaminergic effect of nicotine or may increase the use of antipsychotics medications (Patkar et al., 2002). Furthermore, cholinergic deficits in basal forebrain structures and their projections in schizophrenia may be of particular importance to the cognitive dysfunction given their known functional roles in conscious awareness, and components of information processing, including attention, working memory, encoding, memory consolidation, and retrieval (Gold, 2003; Perry et al., 1999).

Our results showed that the overall prevalence of moderate to high dependence of smoking assessed by the 
FTND score was approximately $88.8 \%$ of participants consuming more than 20 cigarettes per day. Consistent with other studies that showed a high prevalence of smoking in schizophrenia ranged between $72 \%$ and $90 \%$ compared with $24 \%$ of the general population (Evins, 2008; Mitchell \& Dahlgren, 1986). Patients with schizophrenia smoke many more cigarettes on average per day (McCreadie \& Kelly, 2000). In addition, some studies have found that these patients have higher serum levels of cotinine, the primary metabolite of nicotine (Center for Disease Control and Prevention, 2002). Our study also showed that a majority of patients said they enjoyed smoking, it's an essential task that helps them feeling relax. This suggests that a significant proportion of people perceive some benefit from smoking. A recent study revealed that cigarette is a support to face difficulties, cigarette gives pleasure and smoking alleviates the psychiatric symptoms of the medication (Oliveira, Siqueira Júnior, Santos, \& Furegato, 2014).

The findings of this study are consistent with literature indicating that cigarette smoking and relapse to smoking may be more directly associated with reward system dysfunction in psychiatric smokers (Cook, Spring, McChargue, \& Doran, 2010). Previous work in individuals with schizophrenia and other serious mental illnesses has suggested an association also between greater smoking severity and an increased positive symptoms, decreased negative symptoms and fewer extra pyramidal side effects (Dixon et al., 2007), in line with the results of our study. The evidence emerging from this study support the concept that schizophrenic smokers (SWS) who are at high nicotine dependence, may utilize nicotine within cigarettes to ameliorate existing deficits in their reward system. Future studies are needed to replicate and extent these findings in SWS and to search deeper for the mechanisms that might explain high rates of smoking among these psychiatrically ill individuals. Thus, chronic nicotine exposure desensitizes the nicotinic receptors and reduces the cholinergic activity in the prefrontal cortex of schizophrenics which may adversely affect the negative symptoms (Patkar et al., 2002; Vezina, Blanc, Glowinski, \& Tassin, 1992). Smoking is a complex process which involves psychopathological, biochemical and neuropharmacological aspects among schizophrenic patients (Lohr \& Flynn, 1992).

Additionally, despite being the first cause of mortality worldwide and aside from being ethically disturbing and opposing to the recognized standards of medical practice, the use of cigarette can have some benefits; there are ethical and practical concerns if healthcare facilities prohibit smoking without providing alternatives, particularly since withdrawal can alter the presentation of symptoms and response to treatment and may confuse or even exacerbate symptoms. Clinicians should also be aware of the consequences that can result from a lack of cigarettes. These consequences indicate that providers may need to help patients obtain cigarettes and/or monitor usage, although this may result in ethical concerns as well (Keltner \& Grant, 2006; McCloughen, 2003).

\section{Limitations and strengths}

There are some limitations in our study. It's a cross sectional study conducted in one center with a small sample size. The self-report of smoking status, made to measure the smoking status, might be a source of information bias. The years of evolution of schizophrenia and a detailed evaluation of the drugs used for each patient are not taken into account. The importance of this study lies in the fact that it is the first to be conducted in Lebanon to assess the relationship between smoking and schizophrenia symptoms, however, we cannot exclude the possibility that this change could be a result of the medication. It enhances the scientific literature in showing the benefits of smoking on negative symptoms of schizophrenia. Therefore, greater efforts are warranted in this area to discover the impact of tobacco dependence in schizophrenic patients.

\section{Conclusion}

This study is the first to investigate the relationship between the expression of negative symptoms in individuals with schizophrenia and smoking in Lebanon. Moreover, this study alarmingly addresses the high levels of cigarette smoking among patients with schizophrenia. Cigarette smoking rates remain remarkably high in patients with schizophrenia. Nicotine dependence was correlated with the expression of negative symptoms, with an inverse association between the two variables. This emphasizes the reported correlation between the reward system deficits and the impact of nicotine on the negative symptoms. Though our results showed a decrease in negative signs among smoking patients with schizophrenia, yet clinicians should encourage smoking cessation among these patients due to the fact that smoking and nicotine addiction have a very high morbidity and mortality rates. Further investigations are required to justify our findings.

\section{FUNDING}

None.

\section{CONFLICT OF INTEREST}

The authors have nothing to disclose. 


\section{REFERENCES}

Addington, D., Addington, J., \& Maticka-Tyndale, E. (1993). Assessing depression in schizophrenia: the Calgary Depression Scale. The British Journal of Psychiatry. 163 (Suppl 22) 39-44.

Aguilar, M. C., Gurpegui, M., Diaz, F. J., \& De Leon, J. (2005). Nicotine dependence and symptoms in schizophrenia. The British Journal of Psychiatry, 186(3), 215-221.

Al-Halabí, S., Fernández-Artamendi, S., Díaz-Mesa, E., García-Álvarez, L., Flórez, G., Martínez-Santamaría, E., ... Bobes, J. (2017). Tobacco and cognitive performance in schizophrenia patients: the design of the COGNICO study. Adicciones,29(1), 6-12.

American Psychiatric Association. (2013). Diagnostic and Statistical Manual of Mental Disorders (5th Edition). Arlington: author.

Barnes, M., Lawford, B. R., Burton, S. C., Heslop, K. R., Noble, E. P., Hausdorf, K., ... Young, R. M. (2006). Smoking and schizophrenia: is symptom profile related to smoking and which antipsychotic medication is of benefit in reducing cigarette use? Australian and New Zealand Journal of Psychiatry, 40(6-7), 575-580.

Beck, A. K., Baker, A. L., \& Todd, J. (2015). Smoking in schizophrenia: cognitive impact of nicotine and relationship to smoking motivators. Schizophrenia Research: Cognition, 2(1), 26-32.

Carrillo, J. A., Herráiz, A. G., Ramos, S. I., Gervasini, G., Vizcaíno, S., \& Benítez, J. (2003). Role of the smoking-induced cytochrome P450 (CYP) 1A2 and polymorphic CYP2D6 in steady-state concentration of olanzapine. Journal of Clinical Psychopharmacology, 23(2), 119-127.

Center for Disease Control and Prevention. (2002). Annual smoking-attributable mortality, years of potential life lost, and economic costs-United States, 1995-1999. Morbidity and Mortality Weekly Report, 51(14), 300-303.

Changeux, J. P. (2010). Nicotine addiction and nicotinic receptors: lessons from genetically modified mice. Nature Reviews Neuroscience, 11(6), 389-401.

Cook, J., Spring, B., McChargue, D., \& Doran, N. (2010). Effects of anhedonia on days to relapse among smokers with a history of depression: a brief report. Nicotine \& Tobacco Research, 12(9), 978-982

De Leon, J., \& Diaz, F. J. (2005). A meta-analysis of worldwide studies demonstrates an association between schizophrenia and tobacco smoking behaviors. Schizophrenia Research, 76(2), 135-157.

Dépatie, L., O'Driscol, G. A., Holahan, A. L. V., Atkinson, V., Thavundayil, J. X., Kin, N. N., ... Lal, S. (2002). Nicotine and behavioral markers of risk for schizophrenia: a double-blind, placebo-controlled, cross-over study. Neuropsychopharmacology, 27(6), 1056-1070.

Dervaux, A., \& Laqueille, X. (2008). Tabac et schizophrénie: aspects épidémiologiques et cliniques. Smoking and schizophrenia: Epidemiological and clinical features. L'encephale, 34(3), 299-305.

Dickerson, F., Stallings, C. R., Origoni, A. E., Vaughan, C., Khushalani, S., Schroeder, J., ... Yolken, R. H. (2013). Cigarette smoking among persons with schizophrenia or bipolar disorder in routine clinical settings, 1999-2011. Psychiatric Services, 64(1), 44-50.
Dixon, L., Medoff, D. R., Wohlheiter, K., DiClemente, C., Goldberg, R., Kreyenbuhl, J., ... Davin, C. (2007). Correlates of severity of smoking among persons with severe mental illness. The American Journal on Addictions, 16(2), 101-110.

Dome, P., Lazary, J., Kalapos, M. P., \& Rihmer, Z. (2010). Smoking, nicotine and neuropsychiatric disorders. Neuroscience \& Biobehavioral Reviews, 34(3), 295-342.

Drew, A. E., Derbez, A. E., \& Werling, L. L. (2000). Nicotinic receptor-mediated regulation of dopamine transporter activity in rat prefrontal cortex. Synapse, 38(1), 10-16.

Evins, A. E. (2008, March). Nicotine dependence in schizophrenia: prevalence, mechanisms, and implications for treatment. Psychiatric Times. Retrieved from http://www.psychiatrictimes.com/ schizophrenia/nicotine-dependence-schizophrenia-prevalencemechanisms-and-implications-treatment/page/0/1

George, T. P. (2007). Neurobiological links between nicotine addiction and schizophrenia. Journal of Dual Diagnosis, 3(3-4), 27-42.

Glassman, A. H. (1993). Cigarette smoking: implications for psychiatric illness. American Journal of Psychiatry, 150(4), 546-553.

Goff, D. C., Henderson, D. C., \& Amico, E. (1992). Cigarette smoking in schizophrenia: relationship to psychopathology and medication side effects. American Journal of Psychiatry, 149(9), 11891194.

Gold, P. E. (2003). Acetylcholine modulation of neural systems involved in learning and memory. Neurobiology of Learning and Memory, 80(3), 194-210.

Hall, R. G., Duhamel, M., McClanahan, R., Miles, G., Nason, C., Rosen, S., ... Hall, S. M. (1995). Level of functioning, severity of illness and smoking status among chronic psychiatric patients. The Journal of Nervous and Mental Disease, 183(7), 468-471.

Harris, J. G., Kongs, S., Allensworth, D., Martin, L., Tregellas, J., SuIlivan, B., ... Freedman, R. (2004). Effects of nicotine on cognitive deficits in schizophrenia. Neuropsychopharmacology, 29(7), 1378-1385.

Heatherton, T. F., Kozlowski, L. T., Frecker, R. C., \& Fagerström, K. O. (1991). The Fagerström test for nicotine dependence: a revision of the Fagerström Tolerance Questionnaire. British Journal of Addiction, 86(9), 1119-1127.

Jacobsen, L. K., D'Souza, D. C., Mencl, W. E., Pugh, K. R., Skudlarski, P., \& Krystal, J. H. (2004). Nicotine effects on brain function and functional connectivity in schizophrenia. Biological Psychiatry, 55(8), 850-858.

Kao, Y. C., Liu, Y. P., Cheng, T. H., \& Chou, M. K. (2011). Cigarette smoking in outpatients with chronic schizophrenia in Taiwan: relationships to socio-demographic and clinical characteristics. Psychiatry Research, 190(2-3), 193-199.

Kay, S. R., Flszbein, A., \& Opfer, L. A. (1987). The positive and negative syndrome scale (PANSS) for schizophrenia. Schizophrenia bulletin, 13(2), 261-276.

Kelly, C., \& McCreadie, R. (2000). Cigarette smoking and schizophrenia. Advances in Psychiatric Treatment, 6(5), 327-331.

Keltner, N. L., \& Grant, J. S. (2006). Smoke, smoke, smoke that cigarette. Perspectives in Psychiatric Care, 42(4), 256-261. 
Krishnadas, R., Jauhar, S., Telfer, S., Shivashankar, S., \& McCreadie, R. G. (2012). Nicotine dependence and illness severity in schizophrenia. The British Journal of Psychiatry, 201(4), 306312.

Leonard, S., \& Adams, C. E. (2006). Smoking cessation and schizophrenia. American Journal of Psychiatry, 163(11), 1877.

Lohr, J. B., \& Flynn, K. (1992). Smoking and schizophrenia. Schizophrenia Research, 8(2), 93-102.

Lyon, E. R. (1999). A review of the effects of nicotine on schizophrenia and antipsychotic medications. Psychiatric Services, 50(10), 1346-1350.

McCloughen, A. (2003). The association between schizophrenia and cigarette smoking: a review of the literature and implications for mental health nursing practice. International Journal of Mental Health Nursing, 12(2), 119-129.

McCreadie, R. G., \& Kelly, C. (2000). Patients with schizophrenia who smoke. The British Journal of Psychiatry, 176(2), 109.

Mitchell, J. E., \& Dahlgren, L. A. (1986). Prevalence of smoking among psychiatric outpatients. American Journal of Psychiatry, 143(8), 993-997.

Morisano, D., Bacher, I., Audrain-McGovern, J., \& George, T. P. (2009). Mechanisms underlying the comorbidity of tobacco use in mental health and addictive disorders. The Canadian Journal of Psychiatry, 54(6), 356-367.

Mortensen, P. B., \& Juel, K. (1993). Mortality and causes of death in first admitted schizophrenic patients. The British Journal of Psychiatry, 163(2), 183-189.

Nomikos, G. G., Schilström, B., Hildebrand, B. E., Panagis, G., Grenhoff, J., \& Svensson, T. H. (2000). Role of a7 nicotinic receptors in nicotine dependence and implications for psychiatric illness. Behavioural Brain Research, 113(1), 97-103.

Oliveira, R. M. D., Siqueira Júnior, A. C., Santos, J. L. F., \& Furegato, A. R. F. (2014). Nicotine dependence in the mental disorders, relationship with clinical indicators and the meaning for the user. Revista Latinoamericana de Enfermagem, 22(4), 685-692.

Patkar, A. A., Gopalakrishnan, R., Lundy, A., Leone, F. T., Certa, K. M., \& Weinstein, S. P. (2002). Relationship between tobacco smoking and positive and negative symptoms in schizophrenia. The Journal of Nervous and Mental Disease, 190(9), 604-610.
Perry, E., Walker, M., Grace, J., \& Perry, R. (1999). Acetylcholine in mind: a neurotransmitter correlate of consciousness? Trends in Neurosciences, 22(6), 273-280.

Sacco, K. A., Termine, A., Seyal, A., Dudas, M. M., Vessicchio, J. C., Krishnan-Sarin, S., ... George, T. P. (2005). Effects of cigarette smoking on spatial working memory and attentional deficits in schizophrenia: involvement of nicotinic receptor mechanisms. Archives of General Psychiatry, 62(6), 649-659.

Šagud, M., Mihaljević-Peleš, A., Mück-Šeler, D., Pivac, N., Vuksan-Ćusa, B., Brataljenović, T., ... Jakovljević, M. (2009). Smoking and schizophrenia. Psychiatria Danubina, 21(3), 371-375.

Sandyk, R., \& Kay, S. R. (1990). The relationship of negative schizophrenia to parkinsonism. International Journal of Neuroscience, 55(1), 1-59.

Scott, D. J., Domino, E. F., Heitzeg, M. M., Koeppe, R. A., Ni, L., Guthrie, S., ... Zubieta, J.K. (2007). Smoking modulation of $\mu$-opioid and dopamine D2 receptor-mediated neurotransmission in humans. Neuropsychopharmacology, 32(2), 450-457.

Segarra, R., Zabala, A., Eguíluz, J. I., Ojeda, N., Elizagarate, E., Sánchez, P., ... Gutiérrez, M. (2011). Cognitive performance and smoking in first-episode psychosis: the self-medication hypothesis. European Archives of Psychiatry and Clinical Neuroscience, 261(4), 241-250.

Smith, R. C., Singh, A., Infante, M., Khandat, A., \& Kloos, A. (2002). Effects of cigarette smoking and nicotine nasal spray on psychiatric symptoms and cognition in schizophrenia. Neuropsychopharmacology, 27(3), 479-497.

Vezina, P., Blanc, G., Glowinski, J., \& Tassin, J. P. (1992). Nicotine and morphine differentially activate brain dopamine in prefrontocortical and subcortical terminal fields: effects of acute and repeated injections. Journal of Pharmacology and Experimental Therapeutics, 261(2), 484-490.

Zhang, X. Y., Chen, D. C., Xiu, M. H., Haile, C. N., Sun, H., Lu, L., ... Kosten, T. R. (2012). Cigarette smoking and cognitive function in Chinese male schizophrenia: a case-control study. PloS One, 7(5), e36563.

Ziedonis, D. M., Kosten, T. R., Glazer, W. M., \& Frances, R. J. (1994). Nicotine dependence and schizophrenia. Psychiatric Services, 45(3), 204-206. 